\title{
Identificação dos Aspectos Conceituais e Elementos que Constituem o Branding e Destination Branding
}

Lucimari Acosta Pereira

Pablo Flôres Limberger ${ }^{b}$

Luiz Carlos da Silva Flore

\begin{abstract}
Resumo
Com o crescimento acelerado do mercado turístico, o consumidor tem diversas opções de escolha e as empresas visam, por meio de ferramentas como o branding - e no caso do turismo, o destination branding -, posicionar a imagem de seu produto, a fim de obter vantagens competitivas, influenciando a escolha de seu público-alvo. Nesse sentido, este estudo visa compreender e abordar os aspectos conceituais, bem como identificar as variáveis, de branding e destination branding, elencando os processos que os compõe e as linhas de pesquisa abordadas ao longo da evolução dos estudos. Os conceitos foram analisados numa perspectiva longitudinal. Para fazer as incursões exploratórias foi utilizado o método de pesquisa bibliográfica em livros e artigos científicos e realizada uma análise exploratória. Quanto aos resultados, estes apresentaram diversos materiais sobre o tema, embora poucos autores se posicionem conceitualmente seus marcos teóricos. A respeito dos elementos identificados, demonstra-se que há lacunas de pesquisa a serem preenchidas para que se possa dar subsídio teórico e metodológico para novos estudos, além de gerar contribuições gerenciais.
\end{abstract}

Palavras-chave: Branding; Destination Branding; Conceituações; Elementos de composição.

\section{Abstract \\ Identification of Conceptual Aspects and Elements of Branding and Destination Branding}

Due to the fast growth of the tourism market, consumers have several options and companies aim, using tools like branding (in tourism, destination branding), to position their product image and to have competitive advantages, influencing the choice of their target audience. In this sense, this study aims to understand and address the conceptual aspects, as well as to identify the branding and destination branding variables, defining their processes and the research lines addressed throughout the studies. The concepts were analyzed from a longitudinal perspective. To fulfill the research objective, a bibliographic review method in books and scientific articles was used and an exploratory analysis of this study was conducted. The results presented several materials on the subject, although few authors conceptually position themselves on the subject in their

a. Mestre em Turismo e Hotelaria pela Universidade do Vale do Itajaí (Univali). Professora substituta do Instituto de Ciências Humanas e da Informação (ICHI), no curso de Turismo da Universidade Federal do Rio Grande (FURG). Rio Grande, Rio Grande do Sul, Brasil. E-mail: lucimari.svp@gmail.com

b. Doutor em Turismo e Hotelaria na Univali. Professor e pesquisador no Programa de Pós-graduação em Turismo e Hotelaria da Univali. Balneário Camboriú, Santa Catarina, Brasil. E-mail: pflimberger@ gmail.com

c. Pós-doutor pela Universidade do Algarve (Portugal), na área de Turismo. Docente e pesquisador do Programa de Pós-graduação em Turismo e Hotelaria da Univali. E-mail: luiz.flores@univali.br 
theories. The elements identified in this study indicate a gap to be filled in research to allow a theoretical and methodological basis for new studies, as well as generating managerial contributions.

Keywords: Branding; Destination Branding; Conceptualization; Constituting elements. Keywords: Methodology; Tourism research; Tourism under analysis; Turismo em Análise.

\section{Resumen}

Identificación de los aspectos conceptuales y elementos que constituyen el branding y destination branding

Con el crecimiento acelerado del mercado turístico, el consumidor tiene muchas opciones para elegir y las empresas pretenden, a través de herramientas como Branding y, en el caso del turismo, Destination Branding, posicionar la imagen de su producto a fin de obtener una ventaja competitiva al influir en la elección de su público objetivo. En este sentido, este estudio se propone a comprender y abordar los aspectos conceptuales, así como identificar las variables, del Branding y del Branding Destination, listando los procesos que componen las líneas de investigación dirigidas a lo largo de los estudios. Los conceptos fueron analizados en una perspectiva longitudinal. Para cumplir el objetivo de la investigación, se utilizó el método de búsqueda bibliográfica en libros y artículos científicos y se realizaron análisis exploratorios. Los resultados presentaron diversos materiales sobre el tema, aunque pocos autores se posicionen conceptualmente sobre el tema en sus marcos teóricos. Los factores identificados demuestran que existen deficiencias de estudios que deben completarse de modo que puedan dar subsidios teóricos y metodológicos para nuevos estudios, además de generar contribuciones de gestión.

Palabra Clave: Branding Destination; Branding; Conceptualizaciones; Elementos de Composición.

\section{INTRODUÇÃo}

A área do turismo, atualmente globalizada, vem gerando crescimento econômico e se consolida como uma atividade de cunho capitalista com direcionamento para atividades intrinsicamente ligadas ao lazer, tendo como premissa o aproveitamento do tempo livre do indivíduo, que se condiciona também nas atividades de consumo, as quais são ligadas à prática da atividade turística (Elicher \& Bassetti, 2016; Teles, Maffezzolli \& Prado, 2012).

De acordo com a Empresa Brasileira de Turismo (Embratur) (Brasil, 2017), o crescimento do turismo é de relevância mundial para o setor econômico, gerando renda sustentável. Diversas nações se beneficiam pela movimentação do trade turístico como um todo para que a atividade possa acontecer.

Para a manutenção desse crescimento acelerado e das empresas no mercado, várias estratégias de marketing são utilizadas. Uma delas é o destination branding, que se torna um diferencial na promoção do produto e ameniza os riscos associados com a compra, simplificando o processo de tomada de decisão final, seja na escolha de um destino turístico ou de um outro produto associado ou não ao turismo (Pike, 2004; Beni, 2003; 2011; Keller, 2011).

0 branding é um processo de gestão da marca (Keller, 2003). 0 destination branding é uma ferramenta de gestão essencial para as estratégias de marketing de um destino turístico, ressalta as diferenças entre os destinos 
e, assim, cria oportunidades de mercado (Bianchi \& Pike, 2011; Pike, 2013; Moraga, Artigas \& Irigoyen, 2012).

No que se relaciona ao destination branding, Oguztimur e Akturan (2015) abordam que este é a gestão da marca-destino e apontam que os estudos têm sido realizados ao longo dos últimos 30 anos. Os autores ainda abordam que o conhecimento da referida área é de caráter conceitual e empírico, tendo em vista que os gestores vêm buscando ainda respostas de como as cidades podem ser projetadas e gerenciadas como marcas em um mercado atualmente globalizado, dinâmico e competitivo.

A partir da revisão bibliográfica, utilizando livros e artigos científicos, verificou-se a necessidade de se abordar conceitualmente e separadamente as temáticas branding e destination branding, visando apresentar as linhas de pesquisa com a temática, demonstrando a relação do branding e do destination branding com a marca num contexto geral, e almejando também a compreensão desse "processo de gestão", como apontam David Aaker (2007), Anholt (2010), Keller (1993) e Tasci e Denizci (2009) em seus trabalhos.

Sendo assim, este artigo tem como objetivos identificar os aspectos conceituais e variáveis que compõe o branding e o destination branding, mostrando como o turismo vem se apropriando do conceito de branding ao longo dos anos, e como as linhas de pesquisa têm evoluído em suas distintas temáticas, que serão apresentadas no decorrer deste artigo.

Quanto aos aspectos metodológicos, a pesquisa se caracteriza por seu caráter exploratório qualitativo e utilizou-se o método de levantamento e revisão bibliográfica em periódicos, livros e materiais afins que tratam do tema. 0 levantamento de artigos se deu nas plataformas EBSCO, Associação Nacional de Pós-graduação e Pesquisa em Administração (Anpad), Publicações de Turismo, Scielo e Spell.

\section{MÉTODOS}

A pesquisa exploratória, de acordo com Gil (2008), assume, na maioria das vezes, a forma de pesquisa bibliográfica ou estudo de caso. Köche (2011, p. 27), aborda que na "pesquisa exploratória não se trabalha com a relação entre variáveis, mas com o levantamento da presença das variáveis e da sua caracterização quantitativa ou qualitativa".

Já quanto aos métodos de análise, a pesquisa se caracteriza por ser predominantemente qualitativa. 0 método qualitativo, de acordo com Minayo (2008, p. 21), tem como objetivo responder questões e mostrar dados, indicadores e tendências que podem ser observáveis, "ocupando um lugar auxiliar e exploratório sendo, 'subjetivas e impressionistas'”.

A pesquisa foi feita em universo amplo de livros e periódicos, não havendo limitação no que se relaciona a estes suportes. Foram utilizados livros clássicos que tratavam especificamente da temática deste artigo, como Aaker e Shansby (1982), Jennifer Aaker (1997) e Healey (2009).

Quanto aos artigos, foram utilizadas as plataformas Anpad, Scielo, Spell, EBSCO e Publicações de Turismo, que auxiliaram no levantamento de artigos para identificar os elementos que fazem parte do branding e do branding 
destination. Na Figura 1 é demostrado o número de artigos encontrados. A partir deles, foram utilizados os que realmente tratam da temática, apresentado vários elementos e linhas de estudo. 0 levantamento foi feito no segundo semestre de 2016.

Figura 1 - Levantamento de artigos científicos

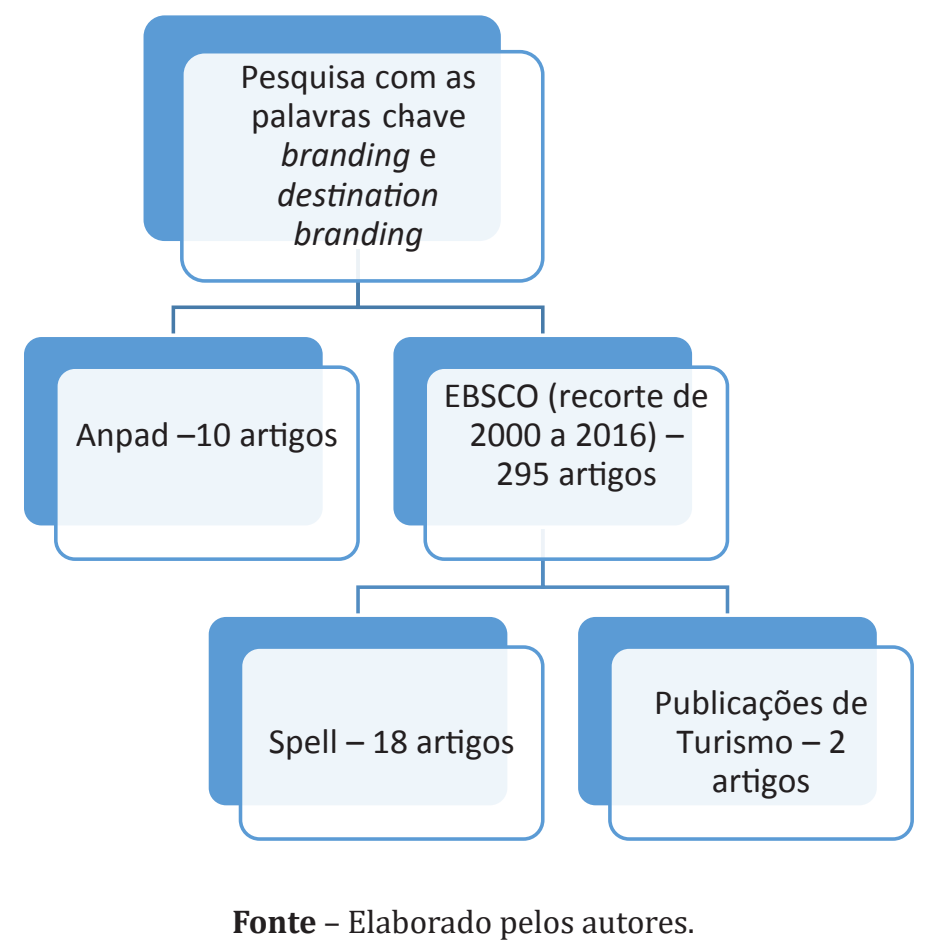

Quanto ao recorte temporal dos artigos, foram selecionados os publicados entre 1950 e 2016. Sendo assim, esta pesquisa traz um recorte longitudinal, demonstrando a evolução do estudo sobre branding e destination branding. Esses artigos deram subsídio para construção do referencial proposto neste artigo.

\section{REFERENCIAL TEÓRICO}

\section{Branding}

A civilização humana depende de sinais, tendo em vista que a mente humana é inseparável do funcionamento destes. Desde então, o branding vem sendo utilizado para dar segurança ao ser humano e, posteriormente, para este como consumidor de forma eficaz, simplificando a tomada de decisão. Trata-se de uma prática milenar: de acordo com relatos, as marcas foram encontradas em China (em cerâmica), Europa e Índia em meados de 1300 a. C. (Keller, 2003; Healey, 2009; Pike, 2013).

Os estudos sobre branding surgiram na literatura de marketing na década de 1940, com Guest (1955), Banks (1950) e Gardner e Levy (1955), mas a grande parte da literatura vem posteriormente, com Aaker (1991; 1996), McEnally (1999), Chernatony (1999), Urde (1999), Aaker e Joachimsthaler (2000), Keller (1993; 2003) e Morgan (2003). Esses trabalhos ainda hoje fornecem um importante 
subsídio tanto na parte gerencial de empresas e organizações quanto para as pesquisas na área acadêmica, em que vêm crescendo mais ainda, com algumas lacunas a serem preenchidas (Pike, 2004; 2009).

No que tange aos conceitos, Healey $(2009$, p. 6) afirma que "Branding é o processo de luta contínua entre produtores e clientes na definição dessa promessa e significado". Nesse contexto, o autor ainda aborda, numa concepção marxista, que "as pessoas tomam as suas próprias decisões sobre quem ser, como viver e o que comprar, mas, em certas circunstâncias, são modeladas pela publicidade e comercialização da marca" (Healey, 2009, p. 6).

Branding, ou gestão de marcas (brand management), é abordado por Keller e Lehmann (2006) como atividades de gestão de suma importância para as organizações de todos os tipos, ressaltando que os estudos são diferenciados e, de forma coletiva, têm avançado na compreensão das marcas. Nesse sentido, branding e gestão de marca tem o mesmo significado e os próprios autores dão os dois tratamentos no que se refere a utilização do termo.

Healey (2009) aborda que o branding tende a promover inúmeras possibilidades, que podem garantir o sucesso do produto ou serviço como: 1) reforçar uma boa reputação; 2) estimular a lealdade; 3) garantir a qualidade; 4) veicular uma percepção de maior valor, permitindo que um produto seja vendido a um preço superior (ou que um produto de valor igual venda mais); e 5) garantir ao comprador uma sensação de afirmação e de uma comunidade imaginária de valores partilhados.

A partir dos elementos elencados anteriormente, o branding deve trabalhar o imaginário do consumidor a partir da imagem posicionada por seus elementos, o que por fim irá reforçar uma boa reputação, estimular a lealdade, assegurar a qualidade, veicular valor e garantir afirmação do produto no mercado como marca forte (Healey, 2009).

Já Martins (2006, p. 8) aborda que:

Branding é o conjunto de ações ligadas à administração das marcas. São ações que, tomadas com conhecimento e competência, levam as marcas além da sua natureza econômica, passando a fazer parte da cultura, e influenciar a vida das pessoas. Ações com a capacidade de simplificar e enriquecer nossas vidas num mundo cada vez mais confuso e complexo.

A prática do branding envolve cinco componentes, que são abordados por Healey (2009, p. 8-9) e descritos a seguir:

Posicionamento, um conceito aplicado pela primeira vez por Al Ries e Jack Trout no seu livro de 1980, significa definir na mente de um cliente o que representa uma marca e de que modo se compara com as marcas rivais. É importante para os produtores se concentrarem no que o cliente pensa e responderem a esse desiderato. É isso que torna o branding um processo bidirecional.

História é o que o homem tem feito há milênios. Todos gostam de uma boa e emotiva história e querem ouvir as melhores vezes sem conta. Quando compramos marcas, participamos na sua história: grandes marcas garantem-nos o papel importante que desempenhamos na sua grande história. 
Design refere-se a todos aspectos de com alguma coisa é criada, não apenas o seu aspecto visual. 0 design é tanto o líquido como o rótulo, tanto o essencial como o nome, o conteúdo e a embalagem. Em geral, quando uma empresa fala de rebranding, está a falar de redesign. Uma verdadeira reformulação da marca implica em redefinir o conceito chave.

Preço é um aspecto vital, embora menos óbvio de uma marca. 0 domínio do preço é fundamental na concorrência.

Atendimento ao cliente representa todos os esforços, por vezes quixotescos, de uma empresa em tornar-nos cada um de nós especial. Isto é fundamental.

No que tange a sua prática dentro do contexto da atividade de marketing, Healey (2009, p. 26), aborda que "o branding é uma destilação de atividades desenvolvidas pela primeira vez no século XIX e XX como marketing, publicidade, relações públicas, design gráfico (dantes chamado de arte gráfica) e identidade corporativa".

Corroborando com os conceitos Barths e Baldissera (2015), apontam que o branding é o gerenciamento de marcas, pelo qual as organizações podem atingir objetivos, expandir e manter-se no mercado, sendo que esse processo de gerenciamento se apresenta como uma ferramenta essencial na construção de valor da marca.

Assim, para ampliar as possibilidades de as organizações atingirem seus objetivos e expandirem as chances de permanência no mercado, os processos de branding (gerenciamento de marcas) apresentam-se fundamentais para a qualificação da gestão na construção de valor para as organizações (Keller \& Lehmann, 2006)

Os autores ainda abordam que o branding é um dos principais processos de gestão da empresa, pois trata de um de seus principais ativos, a marca. Em uma perspectiva acadêmica, os autores abordam que a temática envolve uma gama diferenciada de temas e linhas de pensamentos, trazendo gestão, planejamento e gerenciamento (Keller \& Lehmann, 2006).

As relações do branding com a experiência de consumo e com os aumentos das receitas da empresa já eram feitas por Alexander e Snitzler (1949). Já Banks (1950) abordava a temática em seus estudos quantitativos, nos quais apontava a relação da importância do branding com a decisão de compra do consumidor.

Park, Jaworski e Maclnnis (1986) tratavam da gestão de marca integrando três elementos de formação da mesma introdução, fortificação e elaboração. Esses elementos eram implementados pelo mix marketing visando o posicionamento estratégico e a melhor imagem do produto perante o cliente, almejando, dessa forma, a fidelidade.

Levy (1959) trabalhava o branding no viés da intangibilidade, no qual elencava a importância das interpretações na mente do consumidor com as interpretações. $\mathrm{O}$ autor ainda fazia a abordagem dos bens e seus aspectos simbólicos, em que o comportamento de consumo interferiria de forma direta ou indireta nesse simbolismo. Os estudos na linha da intangibilidade abordam aspectos como imagem, que pode ser real, aspiracional ou experiencial, abarcando assim fatores motivacionais (Maslow, 1970; Keller, 1993; Swarbroke \& Horner, 2002).

Alguns estudos trazem o branding ligado à personalidade da marca, com sua utilização na forma de gestão estratégica promocional - nesse contexto, 
trabalhando elementos como sinceridade, emoção, competência, sofisticação e força. Diversos autores trabalharam em suas pesquisas com marcas já consolidadas e que passam pelo processo de branding (Aaker, 1991; Aaker, J., Martínez \& Garolera, 2001).

Keller e Lehmann (2006) e Alden, Steenkamp e Batra (1999) trabalharam o viés do posicionamento estratégico da marca dentro da cultura de consumo. Os autores acreditam que essa cultura esteja associada a um conjunto de símbolos que, trabalhados de forma estratégica, constituirão uma cultura global de consumo.

Os autores Szabluk, Dziobczenski e Linden (2015) trabalham em suas pesquisas a questão da importância da marca trabalhada pelo viés do designer gráfico. Eles elencaram como a gestão da identidade visual é importante nas estratégias competitivas e como as publicações ainda são escassas na área, o que torna os estudos não apenas viáveis, mas necessários.

Os designers trabalham com a questão da experiência do consumidor. Montaña e Guzmán (2007) abordam que a concepção da marca em uma linha ligada à psicologia reduz os riscos, oferecendo dessa maneira uma experiência diferenciada por meio da marca.

Num foco em estudos na área da administração e gestão de marcas, Porto e Carvalho (2015, p. 230), apontam que "as estratégias de branding passam a ser mais relevantes em períodos pós-lançamento de uma marca”, compreendendo-se assim que o branding, como tratado pelos autores, inicia-se de fato com a inserção da marca no mercado como um dos ativos da empresa. Os autores fazem seus estudos focalizando na inserção de novas marcas no mercado.

Já no turismo, há autores que trabalham o destination branding como experiência de consumo, a qual tem capacidade de designar faces do comportamento do consumidor, que vem relacionado do multissensorial e da fantasia, motivando aspectos da experiência (Hirschman \& Holbrook, 1982; Kozak \& Kozak, 2016; Aaker, D., 2007; Chias, 2007).

Nessa perspectiva, o destination branding é ferramenta importante dentro do contexto do marketing de destinos turísticos. Para as organizações, é uma forma de se diferenciar, o que se torna uma estratégia competitiva significante, pois tem como finalidade construir e projetar uma imagem positiva com ligações emocionais que interferem na experiência vivida pelo turista (Hirschman \& Holbrook, 1982; Kozak \& Lozak, 2016; Aaker, D. 2007; Chias, 2007).

Leão, Camargo e Cavalcanti (2015, p. 16) compreendem que "empreender sobre o conceito da personalidade de marcas brasileiras se revela oportuno estudo em uma agenda de pesquisas na área de branding". Os autores fazem suas pesquisas na área de branding focando na personalidade da marca, utilizando como base Jennifer Aaker (1997). No que tange ao conceito, os autores sintetizam que a personalidade da marca é trabalhada em cima das qualidades relacionadas aos seres humanos (Leão et al., 2015).

Nessa perspectiva de estudos sobre branding, em uma abordagem acadêmica integram posicionamento, valor, desenvolvimento e gestão, entre outros construtos que serão observados no Quadro 1, sendo que todos esses elementos fazem parte do branding e são trabalhados de forma isolada: 
Quadro 1 - Elementos e linhas de pesquisa sobre branding

\begin{tabular}{|c|c|c|}
\hline Elementos & Ações & Autores \\
\hline $\begin{array}{l}\text { Posicionamento } \\
\text { estratégico }\end{array}$ & $\begin{array}{l}\text { O posicionamento da marca define } \\
\text { a direção de atividades e programas } \\
\text { durante sua comercialização, envolvendo } \\
\text { o estabelecimento de associações chave da } \\
\text { marca na mente do consumidor e outros } \\
\text { componentes importantes para diferenciá-la } \\
\text { e estabelecer superioridade competitiva. }\end{array}$ & $\begin{array}{l}\text { Aaker (1982); Alden et } \\
\text { al. (1999); David Aaker e } \\
\text { Shansby (1982); Rajkumar, } \\
\text { Padmanand, Ganesan e } \\
\text { Venugopal (2015) }\end{array}$ \\
\hline Intangibilidade & $\begin{array}{l}\text { A intangibilidade é a forma como os } \\
\text { profissionais de marketing trabalham } \\
\text { a diferenciação da marca na mente do } \\
\text { consumidor, na qual não estão presentes } \\
\text { aspectos físicos, tangíveis e/ou concretos de } \\
\text { seus atributos. }\end{array}$ & Levy $(1959 ; 1999)$ \\
\hline $\begin{array}{l}\text { Relações de } \\
\text { consumo }\end{array}$ & $\begin{array}{l}\text { Esse viés trata da relação da marca como } \\
\text { componente pessoal para os clientes, } \\
\text { determinando diversas relações afetivas e } \\
\text { experienciais vividas por este, influenciando, } \\
\text { dessa forma, a questão da fidelidade. }\end{array}$ & Banks (1950); Levy (1959) \\
\hline $\begin{array}{l}\text { Personalidade da } \\
\text { marca }\end{array}$ & $\begin{array}{l}\text { Nesse contexto, os estudiosos tratam da } \\
\text { questão da personalidade, em que a marca } \\
\text { é estudada por suas dimensões, as quais } \\
\text { possibilitam estudos quantitativos. }\end{array}$ & $\begin{array}{l}\text { Jennifer Aaker (1997; } \\
\text { 1999); Jennifer Aaker et al. } \\
\text { (2001); Leão et al. (2015) }\end{array}$ \\
\hline Competitividade & $\begin{array}{l}\text { Estudo da marca no viés da estratégia } \\
\text { competitiva, na qual a diferenciação desta } \\
\text { traz vantagens sobre outros produtos. }\end{array}$ & Tasci e Denizci (2009) \\
\hline Imagem & $\begin{array}{l}\text { Alguns autores tratam da imagem } \\
\text { transmitida pela marca e como esta } \\
\text { influencia as decisões de compra e consumo. }\end{array}$ & Tasci (2009); Pike (2009) \\
\hline Valor da marca & $\begin{array}{l}\text { Estudo da marca no viés do valor de mercado } \\
\text { e para seus clientes. }\end{array}$ & $\begin{array}{l}\text { Aaker (1991); Pike } \\
\text { (2009) }\end{array}$ \\
\hline $\begin{array}{l}\text { Identidade visual } \\
\text { e comunicação } \\
\text { da marca }\end{array}$ & $\begin{array}{l}\text { A identidade visual é uma ferramenta para } \\
\text { promover estratégias e competitividade em } \\
\text { termos de desempenho. }\end{array}$ & $\begin{array}{l}\text { Szabluk et al. (2015); } \\
\text { Montaña e } \\
\text { Guzman (2007) }\end{array}$ \\
\hline $\begin{array}{l}\text { Turismo como } \\
\text { experiência de } \\
\text { consumo }\end{array}$ & $\begin{array}{l}\text { Nesse viés, trabalha-se o turismo como } \\
\text { experiência de consumo. }\end{array}$ & $\begin{array}{l}\text { Hirschman e Holbrook } \\
\text { (1982); Kozak e Kozak } \\
\text { (2016), David Aaker } \\
\text { (2007); Chias (2007); } \\
\text { Anholt (2010) }\end{array}$ \\
\hline
\end{tabular}

Fonte - Elaborado pelos autores.

\section{Branding destination}

O branding tem como uma de suas finalidades empregar vantagens competitivas ao destino. Dessa maneira, a gestão de marca-destino almeja, por meio de promoções de marketing turístico, externar a identidade e a partir desta trazer efeitos multiplicadores no que se refere à demanda turística (Calvento \& Colombo, 2009). 
A marca-destino não é apenas um elemento que agrega identidade ao destino, mas também é um ativo importante para uma organização, já que influencia aspectos afetivos e cognitivos do indivíduo, desenvolvendo a fidelidade da marca. Sendo assim, a literatura aborda que essa categoria carece de estudos sobre sua consistência e seus processos de gestão, os quais são chamados por alguns autores da literatura internacional de branding destination no caso da área do turismo (Moschis, Moore, \& Stanley, 1984; Keller \& Lehmann, 2006; Aaker, 1991).

0 destination branding, segundo Pike (2009), é um conjunto de atividades de marketing que serve para criar uma imagem positiva do destino, incluindo: 1) criação de um nome, símbolo, marca ou gráfico que represente a identidade do destino e o diferencie dos outros; 2) transmitir de forma consistente a expectativa de uma experiência de uma viagem inesquecível associada ao destino; 3) consolidar e reforçar a conexão emocional entre o visitante e o destino; e 4) reduzir os custos de pesquisa do consumidor e a percepção de risco.

0 destination branding é um processo que traz benefícios tanto para a organização quanto para o cliente, que reforça a capacidade da marca de se diferenciar das outras no mercado aumentando a intenção de compra, criando vantagens competitivas para as organizações, fidelizando o cliente, aumentando rendimentos e beneficiando o turismo local. Para o turista, os benefícios são facilidade na tomada de decisão, custo de pesquisa reduzido e redução de risco e valor da compra (Pike, 2009).

0 destination branding é representado na maioria das vezes por um nome, um símbolo ou pela sua própria identidade cultural. O logo ou símbolo destina-se a identificar produtos ou serviços de qualquer natureza comercial, distinguindo um destino do outro e mostrando seu diferencial, tornando-o competitivo no mercado - que tem hoje um consumidor mais exigente, mas muitas vezes com pouco tempo para a tomada de decisão, momento que a construção de uma marca estrategicamente delineada pode ajudar a simplificar, amenizando os riscos são associados a compra, criando expectativas sobre benefícios e cumprindo a promessa de valor (Aaker, J., 1997; Keller, 1993; Pike, 2004; Tasci \& Kozac, 2006).

Um dos objetivos do destination branding é consolidar imagem, visando que esta ocupe um lugar de destaque na mente do consumidor por meio da memória associativa, representada por uma rede de informações que ativa recordações, levando a associações com a marca e sua identidade. Assim, cria-se um posicionamento com a finalidade de acabar com a desordem de comunicação de marketing dos concorrentes ou substitutos, alcançando a mente do consumidor e influenciando na tomada de decisão referente à escolha de destinos turísticos (Aaker, 1996; Pike, 2004; Keller, 1993).

Por meio do destination branding é possível formar uma identidade para o destino, buscando dar-lhe um significado mais profundo, abarcando valores emocionais e destacando as singularidades, visando novos mercados e estimulando a competitividade. No sentido do diferencial, a favorabilidade, a força e a singularidade que o processo de Branding desempenha são como resposta ao diferencial que distingue o reconhecimento da marca (Yenîpinar \& Yildirim, 2016; Keller, 1993).

Esse reconhecimento desempenha um papel importante na determinação da resposta diferencial que compõe o brand equity, especialmente quando ambientes de decisão estão envolvidos, como no caso do turismo. No processo de 
tomada de decisão, o brand equity ocorre quando o consumidor se familiariza com a marca de forma a ter associações cognitivas favoráveis, fortes e únicas na memória (Yenîpinar \& Yildirim, 2016; Keller, 1993). O branding tem também como um de seus objetivos representar e institucionalizar valores e crenças por meio da personalidade e das dimensões de uma marca.

Por meio do processo de destination branding muitos destinos buscam se diferenciar de outros, utilizando uma logomarca que carregue mensagens cognitivas capazes de estruturar uma identidade, com a finalidade de passar a mensagem certa para tornar o destino economicamente competitivo perante os outros, reforçando uma imagem positiva do destino - sendo que a marca-destino tem influência não apenas no processo de seleção, mas também no comportamento de futuros turistas, direcionando sua construção para um público-alvo (Yenîpinar \& Yildirim, 2016; Avraham \& Ketter, 2015; Vilchez, 2013).

Um destino turístico pode ter a definição de uma unidade espacial, a qual compreende produtos individuais que abarcam particularidades, ou pode ser composto de atividades complexas com oportunidades de vivências, abarcando, assim, a experiência turística. Nesse sentido, o destination branding tem como função essencial criar um conceito para demonstrar a identidade, a personalidade e o caráter distintivo do destino turístico (Gnoth, 2007).

Nesse contexto, Tasci e Denizci (2009), em seus estudos sobre destination branding por meio da imagem, elencam a importância da imagem transmitida pela marca, que desenvolve não apenas vantagens competitivas, mas vantagens competitivas sustentáveis. Já Magnusson, Haas e Zhao (2008) abordam em suas pesquisas que o destination branding neutraliza ruídos causados por outros destinos, o que leva a uma avaliação positiva da imagem do destino.

0 conceito tem sido trabalhado na linha de pesquisa de imagem, em que alguns estudiosos analisam a imagem de destino, como Pimentel, Pinho e Vieira (2006, p. 283), que afirmam que "o estudo da imagem da marca de um destino turístico engloba não somente a área do marketing como também múltiplas disciplinas, dada sua importância na gestão do destino". Dessa maneira, os autores explicitam o quanto é importante a gestão da marca, para a qual os estudos de imagem trazem a possibilidade de gestão "de forma a atender as expectativas dos visitantes, dos residentes e das organizações, gerando o seu desenvolvimento e possibilitando sua permanência no mercado competitivo" (Pimentel et al., 2006, p. 283).

0 destination branding realiza quatro funções de gestão, tratando as marcas como comunicadoras, que representam "uma marca de propriedade, e um meio de diferenciação de produto manifestado em nomes, logotipos e marcas registradas legalmente protegidos" (Hankinson, 2004). As quatro funções do destination Branding definidas por Hankinson (2004) incluem: 1) marcas como comunicadoras, que "representam uma marca de propriedade, e um meio de diferenciação de produto manifestado em nomes, logotipos e marcas registradas legalmente protegidos"; 2) marcas como entidades perceptivas, que apelam aos sentidos, razões e emoções do consumidor; 3) marcas como realçadoras de valor; e 4) marcas como relacionamento, considerando que a marca é construída para ter uma personalidade que lhe permita formar um relacionamento com o consumidor.

O Quadro 2 demonstra as linhas de pesquisa e os autores que efetuam os estudos na área: 
Quadro 2 - Elementos e linhas de pesquisa sobre branding destination dentro da área de turismo

\begin{tabular}{|c|c|c|}
\hline Elementos & Ações & Autores \\
\hline $\begin{array}{l}\text { Posicionamento } \\
\text { estratégico }\end{array}$ & $\begin{array}{l}\text { O posicionamento da marca define a } \\
\text { direção das atividades e programas } \\
\text { durante sua comercialização, envolvendo } \\
\text { o estabelecimento de associações chave da } \\
\text { marca na mente do consumidor e outros } \\
\text { componentes importantes para diferenciá- } \\
\text { la e estabelecer superioridade competitiva. }\end{array}$ & $\begin{array}{l}\text { Easingwood (2007); Otjen } \\
\text { (2013); Nickerson e Moysey } \\
\text { (1999) }\end{array}$ \\
\hline Intangibilidade & $\begin{array}{l}\text { A intangibilidade é a forma como os } \\
\text { profissionais de marketing trabalham } \\
\text { a diferenciação da marca na mente do } \\
\text { consumidor, na qual não estão presentes } \\
\text { aspectos físicos, tangíveis e/ou concretos } \\
\text { de seus atributos }\end{array}$ & $\begin{array}{l}\text { Jennifer Aaker et al. (2001); } \\
\text { Pike (2009) }\end{array}$ \\
\hline $\begin{array}{l}\text { Relações de } \\
\text { consumo }\end{array}$ & $\begin{array}{l}\text { Esse viés trata da relação da marca como } \\
\text { componente pessoal para os clientes, } \\
\text { determinando as diversas relações } \\
\text { afetivas e experienciais vividas por este, } \\
\text { influenciando a questão da fidelidade. }\end{array}$ & $\begin{array}{l}\text { Tasci e Denizci (2009); } \\
\text { Hassan, Hamid e Bohairy } \\
(2010)\end{array}$ \\
\hline $\begin{array}{l}\text { Personalidade } \\
\text { da marca }\end{array}$ & $\begin{array}{l}\text { Nesse contexto, os estudiosos tratam da } \\
\text { questão da personalidade, na qual a marca } \\
\text { é estudada por suas dimensões, as quais } \\
\text { possibilitam estudos quantitativos. }\end{array}$ & $\begin{array}{l}\text { Klabi e Debabi (2011); Ekinci } \\
\text { e Hosany (2006) }\end{array}$ \\
\hline Competitividade & $\begin{array}{l}\text { Estudo da marca no viés da estratégia } \\
\text { competitiva, no qual sua diferenciação traz } \\
\text { vantagens sobre de outros produtos. }\end{array}$ & $\begin{array}{l}\text { Pike (2015); Dimoska e } \\
\text { Trimcev (2012); Pike e Mason } \\
\text { (2011); Bagarić e Žitinić } \\
\text { (2013) }\end{array}$ \\
\hline Imagem & $\begin{array}{l}\text { Alguns autores tratam da imagem } \\
\text { transmitida pela marca e como esta } \\
\text { influencia as decisões de compra e } \\
\text { de consumo }\end{array}$ & $\begin{array}{l}\text { Mariutti e Giraldi (2012); } \\
\text { Trotta, Strehlau e Turolla } \\
\text { (2015); Tasci (2009); Pike } \\
\text { (2009); Carvalho, Salazar } \\
\text { e Ramos (2015); Vrana e } \\
\text { Zafiropoulos (2011); Sezgim } \\
\text { (2008); Sarkar e Singh } \\
\text { (2005); }\end{array}$ \\
\hline Valor da marca & $\begin{array}{l}\text { Estudo da marca no viés do valor de } \\
\text { mercado e para seus clientes. }\end{array}$ & $\begin{array}{l}\text { Gartner e Ruzzier (2011); } \\
\text { Boo, Busser e Baloglu (2009); } \\
\text { Pike e Scott (2009); Chen e } \\
\text { Tseng (2010); Pike (2010) }\end{array}$ \\
\hline $\begin{array}{l}\text { Identidade } \\
\text { visual e } \\
\text { comunicação da } \\
\text { marca }\end{array}$ & $\begin{array}{l}\text { A identidade visual é uma ferramenta para } \\
\text { promover estratégias e competitividade em } \\
\text { termos de desempenho. }\end{array}$ & Cai (2002) \\
\hline $\begin{array}{l}\text { Turismo como } \\
\text { experiência de } \\
\text { consumo por } \\
\text { meio da marca }\end{array}$ & $\begin{array}{l}\text { Nesse viés, trabalha-se o turismo como } \\
\text { experiência de consumo por meio da } \\
\text { marca. }\end{array}$ & $\begin{array}{l}\text { Kozak e Kozak (2016); Aaker } \\
\text { (2007); Chias (2007; Anholt } \\
(2010)\end{array}$ \\
\hline
\end{tabular}

Fonte - Elaborado pelos autores. 
A abordagem de Branding Destination é estudada por diversos autores, que definem o conceito como gestão da marca-destino. Nesse contexto, os autores trabalham em várias linhas - como ocorre em outras áreas -, as quais envolvem posicionamento, imagem, gerenciamento e gestão, design, experiência, relações de consumo, identidade e aspectos tangíveis e intangíveis. Esses estudos são de natureza tanto qualitativa como quantitativa, envolvendo comunidade receptora, turista e setor de governança, entre outros (Aaker, J., 1999; 1997; Aaker, J., et al., 2001; Anholt, 2010; Bagarić \& Žitinić, 2013; Carvalho, Ferreira, Kanazawa, Machado, \& Giraldi, 2016; Kozak \& Baloglu, 2011; Pike, 2009; Pimentel et al., 2006; Tasci \& Denizci, 2009; Vasconcelos, Machado, Almeida, Arruda, \& Matos, 2015).

O Quadro 2 demonstra que os trabalhos específicos sobre destination branding são recentes, com uma delimitação temporal, a partir do levantamento feito, de 17 anos - do período de 1999 a 2016 -, como visto por Pike (2009), que já apontava que os estudos, além de recentes, eram escassos.

Os quadros 1 e 2 demostram os elementos de composição de branding e destination branding identificados na literatura. 0 quadro 1 , a partir de uma bibliografia mais ampla, visou mostrar autores base que trabalham com esses elementos em seus artigos e livros. Já o Quadro 2 demonstra os mesmos elementos dentro da linha de pesquisa da área do turismo, demostrando, que alguns autores que trabalham em outras áreas, como psicologia e administração, também abriram espaço para pesquisas na área específica do turismo.

\section{CONSIDERAÇÕES FINAIS}

A partir da pesquisa bibliográfica, pode-se concluir que o estudo sobre branding tem diversas vertentes, trazendo, assim, uma gama conceitos e abordagens distintas. Este trabalho teve como finalidade mostrar as linhas de pesquisa sobre a temática de branding e branding Destination num contexto geral. Além dos conceitos abordados por distintos autores, notou-se que, de uma forma geral, estes dão subsídio para estudos diversos dentro da referida temática.

Em relação aos conceitos, a leitura dos artigos demonstrou que os autores utilizam a palavra branding, logo, discorrem sobre a marca e seus atributos, bem como seus processos de gestão. Nesse contexto, apontam para uma linha específica de pesquisa com imagem, posicionamento, identidade e relações de consumo, entre outros aspectos, mas não se posicionam quanto ao conceito de branding diretamente nem o apresentam em seus marcos teóricos.

Os elementos identificados mostram uma gama ampla de linhas de pesquisa, tanto com a temática branding como com destination branding. As pesquisas demostraram que autores de distintas áreas utilizam a atividade turística como foco de seus trabalhos e que, apesar de vários artigos publicados na área, principalmente os internacionais, ainda existem lacunas a serem preenchidas e modelos mais completos a serem criados, que se tornam possibilidades de novos estudos. Essas lacunas devem preenchidas para que se possa dar subsídio tanto teórico como metodológico para novos trabalhos, além de contribuições gerenciais para empresas e setor público, ajudando na formulação e inserção de novas políticas públicas para a área do turismo e afins. 
Pode-se concluir, a partir dos conceitos e estudos de Aaker (1991), que o processo de branding é um dos elementos norteadores para o planejamento de estratégias de uma empresa ou dentro do próprio setor público, com propósito de melhorar o valor da marca na mente do público-alvo, visando assim a satisfação do consumidor. Quanto aos quadros sobre branding e destination branding, pode-se notar que pesquisas sobre branding já eram feitas antes das sobre destination branding, que trata da área do turismo.

Este artigo demonstra o quanto faz-se importante o branding, tanto para a organização quanto para o cliente, simplificando os processos gerenciais e de tomada de decisão deste último.

Os trabalhos focados em revisão bibliográfica, como este, têm por objetivo auxiliar futuras pesquisas e os pesquisadores que as conduzirão, bem como demonstrar as lacunas existentes, para que futuros trabalhos possam ser realizados, sugerindo assim novos estudos e linhas de pesquisa. Nesse sentido, recomenda-se pesquisas não somente teóricas, mas aplicadas sobre a temática branding e destination branding, tendo em vista que este artigo buscou contribuir para com os aspectos conceituais do tema.

Pode-se concluir que branding e destination branding são um conjunto de ferramentas de uso do marketing para gestão de marcas, composto de elementos que o fazem completo e visam fortalecer a imagem de uma marca por meio do posicionamento de sua imagem na mente do consumidor.

Torna-se importante evidenciar que, para fundamentação deste trabalho, utilizaram-se bases teóricas internacionais, principalmente no que se relaciona ao estudo de destination branding. 0 levantamento nas bases de dados brasileiras mostrou escassez de material sobre o tema, cabendo um trabalho bibliométrico sobre as produções com foco nessa temática no cenário de publicações na área do turismo. Já na área de branding foi possível identificar um maior volume de materiais na área da administração, os quais deram sustentação teórica para conceituar branding.

Sugere-se um novo estudo com levantamento de variáveis a partir dos elementos aqui expostos, para que deem subsídio a construção de novos modelos teóricos para medir a eficácia da marca por meio do destination branding.

\section{REFERÊNCIAS}

AAKER, D. A. (1991). Managing brand equity. New York : Free Press.

AAKER, D. A. (1996). Building strong brands. New York: Free Press.

AAKER, D. A. (2007). Estratégia de portfólio de marcas. Porto Alegre, RS: Bookman.

AAKER, D. A., \& Joachimsthaler, E. (2000). Brand leadership. New York: Free Press.

AAKER, D. A., \& Shansby, G. (1982). Positioning your product. Business Horizons, 25(3), 56-62.

AAKER, J. L. (1997). Dimensions of brand personality. Journal of Marketing Research, 34(3), 347-356.

AAKER, J. L. (1999). The malleable self: the role of self-expression in persuasion. Journal of Marketing Research, 36, 45-57.

AAKER, J. L., Martínez, V. B., \& Garolera, J. (2001). Consumption symbols as carriers of culture: a study of Japanese and Spanish brand personality constructs. Journal of Personality and Social Psychology, 81(3), 492-508. 
ALDEN, D. L., Steenkamp, J.-B. E., \& Batra, R. (1999). Brand positioning through advertising in Asia, North America, and Europe: the role of global consumer culture.Journal of Marketing, $63,75-87$.

ALEXANDER, R., \& Snitzler, J. (1949). Wholesale buying and merchandising. Journal of Marketing, 14(2), 178-191.

ANHOLT, S. (2010). Handbook on tourism destination branding. Madri, Espanha: OMT.

AVRAHAM, E., \& Ketter, E. (2015). “One-size-fits-all”? Differentiation in destinations' marketing goals and strategies to achieve them. Tourism, 63(3), 337-349.

BAGARIĆ, L., \& Žitinić, D. (2013). Competitiveness of Kvaerner region: challenges for destination management. Tourism and Hospitality Management, 19(2), 217-231.

BANKS, S. (1950). The relation between preference and purchase of brands. Journal of Marketing, 15(2), 145-157.

BARTHS, G., \& Baldissera, R. (2015). Branding e a rede de organizações por articulação conceitual. BrandTrends Journal, 9(9), 70-86.

BENI, M. C. (2003). Globalização do turismo: megatendências do setor e a realidade brasileira. São Paulo, SP: Aleph.

BENI, M. C. (2011). Globalização do turismo: megatendências do setor e realidade brasileira (2a ed.). São Paulo, SP: Aleph.

BIANCHI, C., \& Pike, S. D. (2011). Antecedents of destination brand loyalty for a long-haul market: Australia's destination loyalty among Chilean travelers. Journal of Travel \& Tourism Marketing, 28(7), 736-750.

B00, S., Busser, J., \& Baloglu, S. (2009). A model of customer-based brand equity and its application to multiple destinations. Tourism Management, 30, 219-231.

BRASIL. Ministério do Turismo. Instituto Brasileiro do Turismo. (2017). Embratur [Homepage]. Recuperado de http://bit.ly/1NBc0AE

CAI, L. A. (2002). Cooperative branding for rural destinations for rural destinations. Annals of Tourism Research, 29(3), 720-742.

CALVENTO, M., \& Colombo, S. S. (2009). La marca-ciudad como herramienta de promoción turística. ¿Instrumento de inserción nacional e internacional? Estudios y perspectivas en turismo, 18(3), 262-284.

CARVAlHO, D. T., Ferreira, L. B., Kanazawa, F. N., Machado, P. M., \& Giraldi, J. (2016). Experiência em website de marca-país e a formação da imagem de destino turístico: um estudo na Islândia. Revista Brasileira de Pesquisa em Turismo, 10(1), 108-128.

CARVALHO, P. C., Salazar, A. M., \& Ramos, P. M. (2015). Modelo conceptual integrativo de destination branding: teste empírico no Porto e Norte de Portugal. Revista de Turismo y Patrimonio Cultural, 13(4), 865-864.

CHEN, C.-F., \& Tseng, W.-S. (2010). Exploring customer-based airline brand equity: evidence from Taiwan. Transportation Journal, 49(1), 24-34.

CHERNATONY, L. D. (1999). Brand management through narrowing the gap between brand identity and brand reputation. Journal of Marketing Management, 1-3(15), 157-179.

CHIAS, J. (2007). Turismo: o negócio da felicidade. São Paulo, SP: Senac.

DIMOSKA, T., \& Trimcev, B. (2012). Competitiveness strategies for supporting economic development of the touristic destination. Procedia: Social and Behavioral Sciences, 44, 279-288.

EASINGWOOD, C. (2007). Positioning of wine regions: Old or New World branding models? Anais, XIV Vineyard Data Quantification Society Colloquium (pp. 1-10), 2007, Tréveris, RP. Collioure, França: VDQS. 
EKINCI, Y., \& Hosany, S. (2006). Destination personality: an application of brand personality to tourism destinations. Journal of Travel Research, 45(2), 127-139.

ELICHER, M. J., \& Bassetti, T. B. (2016). Turismo e campesinato na cidade de Colombo, PR, Brasil: (co)existência marcada por tempos diferenciados. Revista Turismo em Análise, 27(3).

GARDNER, B., \& Levy, S. (Março/Abril de 1955). The product and the brand. Harvard Business Review, 33-39.

GARTNER, W. C., \& Ruzzier, M. K. (2011). Tourism destination brand equity dimensions: renewal versus repeat market. Journal of Travel Research, 50(5), 471-481.

GIL, A. C. (2008). Métodos e tecnicas de pesquisa social. São Paulo: Atlas.

GNOTH, J. (2007). The Structure of destination brands: leveraging values. Tourism Analysis, 12(5), 345-358.

GUEST, L. (1955). Brand loyalty: twelve years later.Journal of Applied Psychology, 39, 405-408.

HANKISON, G. (2004). Relational network brands: towards a conceptual model of place brands. Journal of Vacation Marketing, 10(2), 109-121.

HASSAN, S. B., Hamid, M. S., \& Bohairy, H. A. (2010). Perception of destination branding measures: a case study of Alexandria destination marketing organizations. International Journal of Euro-Mediterranean Studies, 3(2), 269-288.

HEALEY, M. (2009). O que é Branding? (Gustavo Gili, editor). Barcelona: Roto Vision.

HIRSCHMAN, E. C., \& Holbrook, M. B. (1982). Hedonic consumption: emerging concepts, methods and proposition. Journal of Marketing, 46(3), 92-101.

KELLER, K. L. (1993). Measuring, and managing customer-based brand equity. Journal of Marketing, 57(1), 1-22.

KELLER, K. L. (2003). Brand synthesis: the multi-dimensionality of brand knowledge. Journal of Consumer Research, 29, 595-600.

KELLER, K. L. (2011). Brand strategy. In V. Shankar, \& G. S. Carpenter, editors. Handbook of marketing strategy (pp. 289-305), Cheltenham: Edward Elgar.

KELLER, K. L., \& Lehmann, D. R. (2006). Brands and branding: research findings and future priorities. Marketing Science, 25(6), 740-759.

KLABI, F., \& Debabi, M. (2011). Brand personality and emotional attitudes: the case of mobile telephone operators. Journal of Global Marketing, 24, 245-262.

KÖCHE, J. C. (2011). Fundamentos de metodologia científica: teoria da ciência e iniciação à pesquisa. Petrópolis, RJ: Vozes.

KOZAK, M., \& Baloglu, S. (2011). Managing and marketing tourist destinations: strategies to gain a competitive edge. Nova York, NY: Routledge.

KOZAK, M., \& Kozak, N. (Eds.). (2016). Destination marketing: an international perspective (Série Routledge Advances in Tourism). Londres, Inglaterra; Nova York, NY: Routledge.

LEÃO, A. L. M. S., Camargo, T. I., \& Cavalcanti, R. C. T. (2015). Identidades culturais de consumidores da Pitú em sua comunidade de marca: uma etnografia da comunicação. Revista Gestão Organizacional, 8(2), 60-81.

LEVY, S. J. (1959). Symbols for sales. Harvard Business Review, 37(4), 117-124.

LEVY, S. J. (1999). Brands, consumers, symbols, and research: Sydney J. Levy on Marketing. Thousand Oaks, CA: Sage.

MAGNUSSON, P., Haas, S. M., \& Zhao, H. (2008). A branding strategy for emerging market firms entering developed markets. Journal of International Consumer Marketing, 20, 95-107. 
MARIUTTI, F. G., \& Giraldi, J. (2012). Análise da imagem do brasil por meio do Anholt Nation Branding Index. Revista Turismo Visão e Ação, 14(1), 67-81.

MARTINS, J. R. (2006). Branding: o manual para você criar, gerenciar e avaliar marcas (3a ed.). São Paulo, SP: Copyright.

MASLOW, A. H. (1970). Motivation and personality (2a ed.). Nova York, NY: Harper \& Row Publishers.

MCENALLY, D. M. (1999). The evolving nature of branding: consumer and managerial considerations. Academy of Marketing Science Review, (2).

MINAYO, M. C. S. (Org.). (2008). Pesquisa social: teoria, método e criatividade. Petrópolis, RJ: Vozes.

MONTAÑA, J., \& Guzman, F. (2007). Branding and design management: a brand design management model. Journal of Marketing Management, 23(9), 829-840.

MORAGA, E. T., Artigas, E. A., \& Irigoyen, C. C. (2012). Desarrollo y propuesta de una escala para medir la imagen de los destinos turísticos (Imatur). Revista Brasileira de Gestão de Negócios, 14(45), 400-418.

MORGAN, M. S. (2003). Promotional evaluation and response among variety seeking segments. Journal of Product \& Brand Management, 12, 408-425.

MOSCHIS, G. P., Moore, R. L., \& Stanley, T. J. (1984). An exploratory study of brand loyalty development in NA. Advances in Consumer Research, 11, 412-417.

NICKERSON, P., \& Moysey, N. (1999). Branding a state from features to positioning: making it simple? Journal of Vacation Marketing, 5(3), 217-226.

OGUZTIMUR, S., \& Akturan, U. (2015). Synthesis of city branding literature (1988-2014) as a research domain. International Journal of Tourism Research, 18(4), 357-372.

OTJEN, A. (2013). Positioning and branding a wilderness tourist attraction to meet all stakeholders objectives. Tourismos: an International Multidisciplinary Journal of Tourism, 8(3), 129-150.

PARK, C. W., Jaworski, J. B., \& Maclnnis, D. (1986). Strategic brand concept-image management. Journal of Marketing, 50(4), 135-145.

PIKE, S. D. (2004). Destination brand positioning slogans: towards the development. Acta Turística, 16(2), 102-124.

PIKE, S. D. (2009). Destination brand positions of a competitive set of near-home destinations. Tourism Management, 30(6), 857-866.

PIKE, S. D. (2010). Destination branding case study: tracking brand equity for an emerging destination between 2003 and 2007. Journal of Hospitality \& Tourism Research, 34(1), 124-139.

PIKE, S. D. (2013). Measuring a destination's brand equity between 2003 and 2012 using the consumer-based brand equity (CBBE) hierarchy. Anais, 8. Consumer Psychology in Tourism, Hospitality \& Leisure Research Symposium (pp. 1-22), 2013, Istambul, Turquia. Wallingford, Inglaterra: Cabi.

PIKE, S. D. (2015). Destination brand performance measurement over time: tracking consumer perceptions of a competitive set of destinations over a 10 year period. Acta Turística, 27(1), 135-164.

PIKE, S. D., \& Mason, R. (2011). Destination competitiveness through the lens of brand positioning: the case of Australia's Sunshine Coast. Current Issues in Tourism, 14(2), 169-182.

PIKE, S. D., \& Scott, N. (2009). Destination brand equity among the host community: a potential source of competitive advantage for DMOs - The case of Brisbane, Australia. Acta Turística, 21, 123-250. 
PIMENTEL, E., Pinho, T., \& Vieira, A. (2006). Imagem da marca de um destino turístico. Revista Turismo Visão e Ação, 8(2), 283-298.

PORTO, R. B., \& Carvalho, G. P. (2015) Dinâmicas de participação de mercado durante o lançamento de novas marcas em produtos de compra rotineira. Revista de Administração e Inovação, 12(4), 205-231.

RAJKUMAR, S., Padmanand, V., Ganesan, P., \& Venugopal, P. (2015). Employer branding dimensions: a discriminant analysis approach in campus recruitment. Global Management Review, 10(1), 71-83.

SARKAR, A. N., \& Singh, J. (2005). New paradigm in evolving brand management strategy. Journal of Management Research, 5(2), 80-90.

SEZGIN, E. (2008). Brand image management: perceptions of European tour operators in single tourism market concept. Tourism Preliminary Communication, 56(2), 173-183.

SWARBROOKE, J., \& Horner, S. (2002). O comportamento do consumidor no turismo. São Paulo, SP: Aleph.

SZABLUK, D., Dziobczenski, P. R., \& Linden, J. C. (2015). Branding e design Estado da Arte em periódicos brasileiros de design. BrandTrends Journal, 9(9), 116-127.

TASCI, A. D. (2009). Social distance: the missing link in the loop of movies, destination image, and tourist behavior? Journal of Travel Research, 47, 494-507.

TASCI, A. D., \& Denizci, B. (2009). Destination branding input-output analysis: a method of evaluating productivity. Tourism Analysis, 14, 1-19.

TASCI, A. D., \& Kozak, M. (2006). Destination brands vs destination images: do we know what we mean? Journal of Vacation Marketing, 12(4), 299-317.

TELES, M. I., Maffezzolli, E. C., \& Prado, P. H. (2012). Customer-based brand equity de destinos turísticos: um estudo sobre Foz. Revista Turismo em Análise, 26(3), 166-186.

TROTTA, S. F., Strehlau, V. I., \& Turolla, F. D. (2015). As mudanças na imagem das cidades de Curitiba e Florianópolis: um estudo sobre os reflexos da divulgação das cidades sedes para a Copa do Mundo da Fifa de 2014. Revista Turismo Visão e Ação, 17(2), 279-300.

URDE, M. (Abril de 1999). Brand orientation: a mindset for building brands into strategic resources. Journal of Marketing Management, 15, 117-133.

VASCONCELOS, A. I., Machado, D., Almeida, S. R., Arruda, D. M., \& Matos, F. R. (2015). 0 papel das experiências de consumo na construção da imagem das marcas: um estudo nas companhias aéreas. Revista Brasileira de Pesquisa em Turismo, 9(1), 138-155.

VILCHEZ, J. R. (2013). Valuing tourist destinations: an Oaxaca-Blinder approach. International Journal of Tourism Research, 15(5), 417-429.

VRANA, V., \& Zafiropoulos, K. (2011). Associations between USPs and design characteristics of Mediterranean countries' websites. Journal of Hospitality Marketing \& Management, 20, 766-790.

YENÎPINAR, Y. D., \& Yildirim, Ö. G. (2016). Destinasyon Markalaşmasında Yerel Simgelerin Logo ve Amblemlerde Kullanılması: Muğla Araştırması. Seyahat ve Otel İşletmeciliği Dergisi, 13(1), 28-46. 


\section{CONTRIBUIÇÃo}

Lucimari Acosta Pereira: redação, desenvolvimento de pesquisa teórica em bases de dados e livros sobre o tema, desenvolvimento da problemática, emprego de método qualitativo e desenvolvimento das considerações finais.

Pablo Flôres Limberger: orientação e revisão do manuscrito.

Luiz Carlos da Silva Flores: orientação e revisão do manuscrito 